\title{
Adsorption studies for the simultaneous removal of arsenic and selenium using naturally prepared adsorbent materials
}

\author{
L. D. Mafu • T. A. M. Msagati • B. B. Mamba
}

Received: 11 September 2012/Revised: 28 May 2013/Accepted: 8 September 2013/Published online: 15 October 2013

(C) Islamic Azad University (IAU) 2013

\begin{abstract}
The adsorption properties of eggshell membranes (ESM), eggshells (ES) and orange peels (OP) were studied for the removal of arsenic (total As) and selenium (total Se). The effect of chemical treatment of these adsorbents by $\mathrm{HNO}_{3}$ and $\mathrm{NaOH}$ was also investigated using Fourier transform infrared spectroscopy (FT-IR). Analysis of the FT-IR spectra showed that treatment with $\mathrm{NaOH}$ and $\mathrm{HNO}_{3}$ had an effect on the functional groups present in the materials and also on the adsorption by extension. Thermal analysis showed that ES were more thermally stable than the others with no water molecules in their matrix, which could have caused a substantial weight loss at around $70{ }^{\circ} \mathrm{C}$. In terms of adsorption capacities, chemical treatment increased the adsorption capacities of ESM and OP achieving up to $170 \mu \mathrm{g} \mathrm{g}^{-1}$ (As) and $160 \mu \mathrm{g} \mathrm{g}^{-1}$ (Se), and $120 \mu \mathrm{g} \mathrm{g}^{-1}$ (As) and $70 \mu \mathrm{g} \mathrm{g}^{-1}$ (Se), respectively, with not much activity for ES in terms of adsorption. The two adsorbents ( $\mathrm{NaOH}$-treated OP and ESM) were then tested in environmental water samples and the results showed that $68.9 \%$ of As and $74.8 \%$ of Se, and $54.1 \%$ of $\mathrm{As}$ and $47.3 \%$ of $\mathrm{Se}$ were removed from domestic wastewater samples investigated using OP and ESM, respectively. Moreover, better selectivities towards the compounds of interest were achieved.
\end{abstract}

Keywords Eggshell · Eggshell membranes · Orange peels $\cdot$ Oxyanions

L. D. Mafu · T. A. M. Msagati $(\bowtie) \cdot$ B. B. Mamba Department of Applied Chemistry, Faculty of Science, University of Johannesburg, Doornfontein Campus, P.O. Box 17011, Johannesburg 2028, South Africa

e-mail: tmsagati@uj.ac.za

\section{Introduction}

Trace metal contamination of most water sources has intensified the effect of the scarcity of safe/potable water for human consumption (Richardson 2001; Richardson and Ternes 2011; Chen and An 2012; Kamsonlian et al. 2012; Igwe et al. 2008). Arsenic and selenium have been identified as two of the most toxic trace metals and are found in most aqueous environments with deficiencies closely associated with toxic levels (Peak 2006; Li et al. 2012; Jain and Ali 2000; Hamilton 2004). Through various mechanisms, these trace metals tend to leach into groundwater environments and they also find their way into wastewater treatment systems where they receive minimal attention in terms of treatment (Haque and Johannesson 2006; Mistry et al. 2012). Their toxicity increases from the bottom to the top of the food chain, due to their ability to bio-magnify in organisms and up along the various trophic levels of the food chain. The World Health Organisation (WHO) has recommended the maximum contaminant level (MCL) of $10 \mu \mathrm{g}^{-1}$ for total arsenic and $40 \mu \mathrm{g}^{-1}$ for total selenium in drinking water (World Health Organisation 2008). However, for wastewater effluents, the recommended MCL is $100 \mu \mathrm{g}^{-1}$ for both As and Se (Jain and Ali 2000).

Adsorption is one of the methods that has been recommended for the removal of metals present in water matrices (Li et al. 2012; Babel and Kurniawan 2003; Chen and An 2012). However, though it may be perceived as the easiest process, challenges such as low adsorption capacities, high capital costs, possibility of back-contamination by the adsorbent and the generation of highly contaminated sludge still call for more research to be done to improve the water treatment technologies (Li et al. 2012; Banerjee et al. 2008; Manna and Ghosh 2007; Feng et al. 2009). 
Arsenic and selenium adsorption has been well studied (Jain and Ali 2000; Ladeira and Ciminelli 2004; Bleiman and Mishael 2010; Liu et al. 2012; González et al. 2011; Tian et al. 2011; Yigit et al. 2012; Chen and An 2012); however, the use of low-cost materials in these studies has been minimal, thus making the treatment procedures too expensive or inapplicable to environmental water treatment systems, especially in the developing communities (Zhang et al. 2010). The adsorbents that have been used include activated alumina (Hung et al. 2004), hydrous cerium oxide nanoparticles ( $\mathrm{Li}$ et al. 2012), magnetic wheat straw (Tian et al. 2011), granular ferric hydroxide (Banerjee et al. 2008) and hydrous stannic oxide (Manna and Ghosh 2007). However, some other remediation techniques such as coagulation and filtration, lime softening and ion-exchange resins amongst others have also been studied (Litter et al. 2010).

Low-cost adsorbents such as agricultural wastes and other plant materials have the potential of removing different types of pollutants present in water. Adsorbents such as peanut husks (Ngah and Hanafiah 2008), orange peels (Feng et al. 2009; Dhakal et al. 2005; Lasheen et al. 2012; Yigit et al. 2012) and eggshell membranes (Cheng et al. 2011; Zhang et al. 2010) can be used for the adsorption of toxic materials from water, such as copper, cadmium, lead, nickel and zinc, amongst others. Eggshell membranes and orange peels are abundantly available with the eggshell membranes being available throughout the year whilst the orange peels are seasonal, yet the output when in season is too high to ignore. Latest studies showed that dehydrated aquatic plants (Deng et al. 2013) and spent coffee grains (Cerino-Córdova et al. 2013) could also be used as lowcost adsorbents. Utilising such materials is desirable for providing cheap techniques suitable for the removal of contaminants present in water (Abdel et al. 2011; Love and Thatcher 1953).

Eggshells (ES), eggshell membranes (ESM) and orange peels (OP) have been found to have various functional groups, which would possibly favour the adsorption of negatively charged species (Feng and Guo 2012; Tsai et al. 2006). Eggshells have been found to have mainly carbonyl functionality, whilst eggshell membranes have $-\mathrm{OH},-\mathrm{NH}_{2}$, $-\mathrm{COOH}$ and a high surface area to boost their adsorption abilities in addition to the carbonyl functional group (Tsai et al. 2006). On the other hand, orange peels are mainly composed of hemicellulose, pectin and lignin, and contain the functional groups $-\mathrm{COOH},-\mathrm{COOCH}_{3},-\mathrm{COO}-,-\mathrm{OH}$ (Feng et al. 2009; Feng et al. 2011). All these functional groups play a part in the shaping of the adsorption sites to suit the 'needs' of the adsorbate under study.

The work presented here was conducted at the Department of Applied Chemistry, University of Johannesburg, between the period covering February to July 2012 and it investigates the simultaneous adsorption of the highly toxic arsenic and selenium trace metals using ES, ESM and OP as low-cost adsorbents. The work also focuses on the effect of chemical treatment on the adsorption using only $\mathrm{HNO}_{3}$ and $\mathrm{NaOH}$. To the best of our knowledge, no such study has been carried out and reported elsewhere with regard to the use of these adsorbents for the simultaneous removal of As and Se.

\section{Materials and methods}

\section{Chemicals}

Nitric acid (65\%), hydrochloric acid (32\%), sodium hydroxide, arsenic powder and selenium metal were supplied by Merck (Darmstadt, Germany), and they were all of analytical grade (AR) and were used as supplied without any further purification. Deionised water $(18.4 \mathrm{M} \Omega$ conductivity) was obtained from an in-house reverse osmosis system and was used for most dilutions and the preparation of standards.

\section{Instrumentation}

The determination of metal concentrations was performed with inductively coupled plasma optical emission spectroscopy (ICP-OES) (Wirsam Scientific, GBC Quantima Series ICP connected to a GBC SDS 720 autosampler). Scanning electron microscope (SEM) analyses were carried out using SEM (Tescan) to determine the surface morphology of the materials, whilst Thermo Scientific (Nicolet IS 10) Fourier transform infrared (FT-IR) spectroscopy was used for functional group characterisation. The thermogravimetric analysis was performed using a PerkinElmer TGA 400.

\section{Chemical modification of adsorbents}

Eggs and oranges were bought from local supermarkets around the City of Johannesburg, South Africa. Albumin (egg white) and egg yolk were removed from the eggs, and then the shells were rinsed 5 times with deionised water. The eggshell and eggshell membranes were separated by hand, and thereafter dried in an oven at $80{ }^{\circ} \mathrm{C}$, and then ground and sieved through a 45 mesh. The oranges were peeled, diced and oven-dried at $80{ }^{\circ} \mathrm{C}$ overnight, and then ground and sieved through a 45 mesh. These adsorbents were then sonicated in $0.1 \mathrm{M} \mathrm{HNO}_{3}$ to remove any As and Se that could be present, and rinsed with deionised water until a $\mathrm{pH}$ of 7 was attained.

The adsorbents were further treated with $0.05 \mathrm{M} \mathrm{HNO}_{3}$ and $0.05 \mathrm{M} \mathrm{NaOH}$ overnight, filtered and repeatedly rinsed with deionised water until a $\mathrm{pH}$ of 7 was attained. To 
ascertain the quality of adsorbents after chemical modification, these adsorbents were then analysed by FT-IR to track the functional group changes in the treated and untreated adsorbents.

\section{Batch adsorption experiments}

Batch adsorption experiments were carried out by mixing $0.5 \mathrm{~g}$ of adsorbent in a $100 \mathrm{ml}$ solution containing As and $\mathrm{Se}$ in the desired concentration at a temperature of $25{ }^{\circ} \mathrm{C}$ for $2 \mathrm{~h}$, and shaking the mixture. The effects of $\mathrm{pH}$ on desorption were investigated in the $\mathrm{pH}$ range of $4-11$. Adsorption isotherm experiments were performed at $25{ }^{\circ} \mathrm{C}$ by using $0.5 \mathrm{~g}$ of adsorbent in $100 \mathrm{ml}$ solution of varying concentrations of As and Se $\left(150\right.$ and $\left.800 \mu \mathrm{g} \mathrm{l}^{-1}\right)$. The effect of contact time on the adsorption capacity was studied by varying the exposure time from $10 \mathrm{~min}$ to 300 min and kinetic modelling was then used to evaluate the generated data. After every adsorption or desorption experiment, the solutions were filtered using $0.45-\mu \mathrm{m}$ porous membrane filters and the residue was analysed for As and Se using ICP-OES, and adsorption capacity (AC) was calculated using:

$\mathrm{AC}=\left(C_{0}-C_{\mathrm{f}}\right) \frac{V}{m}$

where $C_{0}$ is the initial concentration; $C_{\mathrm{f}}$ is the final concentration after adsorption; $V$ is the sample volume (l); $m$ is the mass of adsorbent $(\mathrm{g})$.

All adsorption and desorption experiments were done in triplicate and the average values were reported.

\section{Desorption and regeneration tests}

To study the possible reuse of these adsorbents, desorption studies and regeneration tests were performed. Two desorption reagents, $\mathrm{NaOH}$ and $\mathrm{HNO}_{3}$, were investigated. The As/Se-loaded adsorbents were filtered and transferred to a stoppered conical flask with $100 \mathrm{ml}$ of $0.1 \mathrm{M} \mathrm{NaOH}$ and $\mathrm{HNO}_{3}$, then sonicated, and filtered again and the residue determined for the amount of As and Se present. For reuse, the adsorbents were washed using deionised water until a constant $\mathrm{pH}$ of 7 was reached.

\section{Results and discussion}

Materials characterisation

\section{Surface characterisation}

In adsorption, either batch or column, the surface morphology of the adsorbent plays a significant role in the adsorption process. The surface texture and morphology of ESM, ES and OP were found to differ from one another, as shown in Fig. 1, with OPs showing a more fibrous surface than ESM, whilst ES shows a more uniform fibre-free surface. Although the surface areas of OPs were very fibrous, their structure was found to be more regular than the highly irregular yet fibrous surface structure of the ESM. This could either enhance the surface area for adsorption or have an effect on the adsorption sites for As and Se.

\section{Fourier transform infrared (FT-IR)}

The presence or absence of certain functional groups in adsorbents does play a major role in the adsorption of different adsorbates (Abdel et al. 2011). In this study, FTIR spectroscopy was used to determine the type of functional groups present in each adsorbent used and also to follow the chemical modification of the adsorbents using both $\mathrm{NaOH}$ and $\mathrm{HNO}_{3}$ as presented in Fig. 2. The untreated adsorbents showed a constitution of functional groups with distinct differences amongst the three adsorbents. OPs showed a broad peak at $3309 \mathrm{~cm}^{-1}$, which could be associated with the highly dense - $\mathrm{OH}$ functionality of the hemicellulose, pectin and water molecules. The peak at $2,919 \mathrm{~cm}^{-1}$ could be a result of the $\mathrm{C}-\mathrm{H}$ stretching vibrations of $-\mathrm{CH} 3,-\mathrm{CH} 2$ and $-\mathrm{CH}$, and the peak at $1,737 \mathrm{~cm}^{-1}$ shows the presence of $\mathrm{C}=\mathrm{O}$ of ketones or aldehydes and amides. The peaks at 1,607 and $1,418 \mathrm{~cm}^{-1}$ are as a result of the presence of $\mathrm{C}=\mathrm{C}$ of arenes possibly from the presence of limonene and $\alpha-\mathrm{CH}_{3}$, respectively. However, the ES only showed a broad band at $1,500 \mathrm{~cm}^{-1}$ signifying the presence of carbonates and amides, and a few other peaks in the fingerprint region. ESM has amides, amines, carbonates and carboxylic acids as evidenced by the presence of peaks at 3,285, 2,352, 1,631 and $1,418 \mathrm{~cm}^{-1}$.

The modifications of these adsorbents were also evident from the emergence of new peaks or the disappearance of old peaks signifying the modification of functional groups, and hence a possibility of an improvement in the adsorption kinetics or capacity. Treatment of OPs with $\mathrm{NaOH}$ mainly resulted in the shift in infrared absorbance of these materials. The peaks at $746,1,005,1,418,1,607$ and $1,737 \mathrm{~cm}^{-1}$ disappeared and shifted to $766,1,002,1,414$, 1,614 and $1,732 \mathrm{~cm}^{-1}$, respectively. The peak at $1,645 \mathrm{~cm}^{-1}$ disappeared and the peak at $1,605 \mathrm{~cm}^{-1}$ appeared instead. This shows the modification of $\mathrm{C}=\mathrm{O}$ into $\mathrm{C}=\mathrm{C}$ or the modification of the amides to amines. In addition, it was observed that the peak at $1,229 \mathrm{~cm}^{-1}$ due to $\mathrm{C}-\mathrm{N}$ disappeared. When treated with $\mathrm{HNO}_{3}$, OPs showed a shift in the peak position, from 1,606 to $1,645 \mathrm{~cm}^{-1}$ and the peak at $1,732 \mathrm{~cm}^{-1}$ due to $\mathrm{C}=\mathrm{O}$ was 

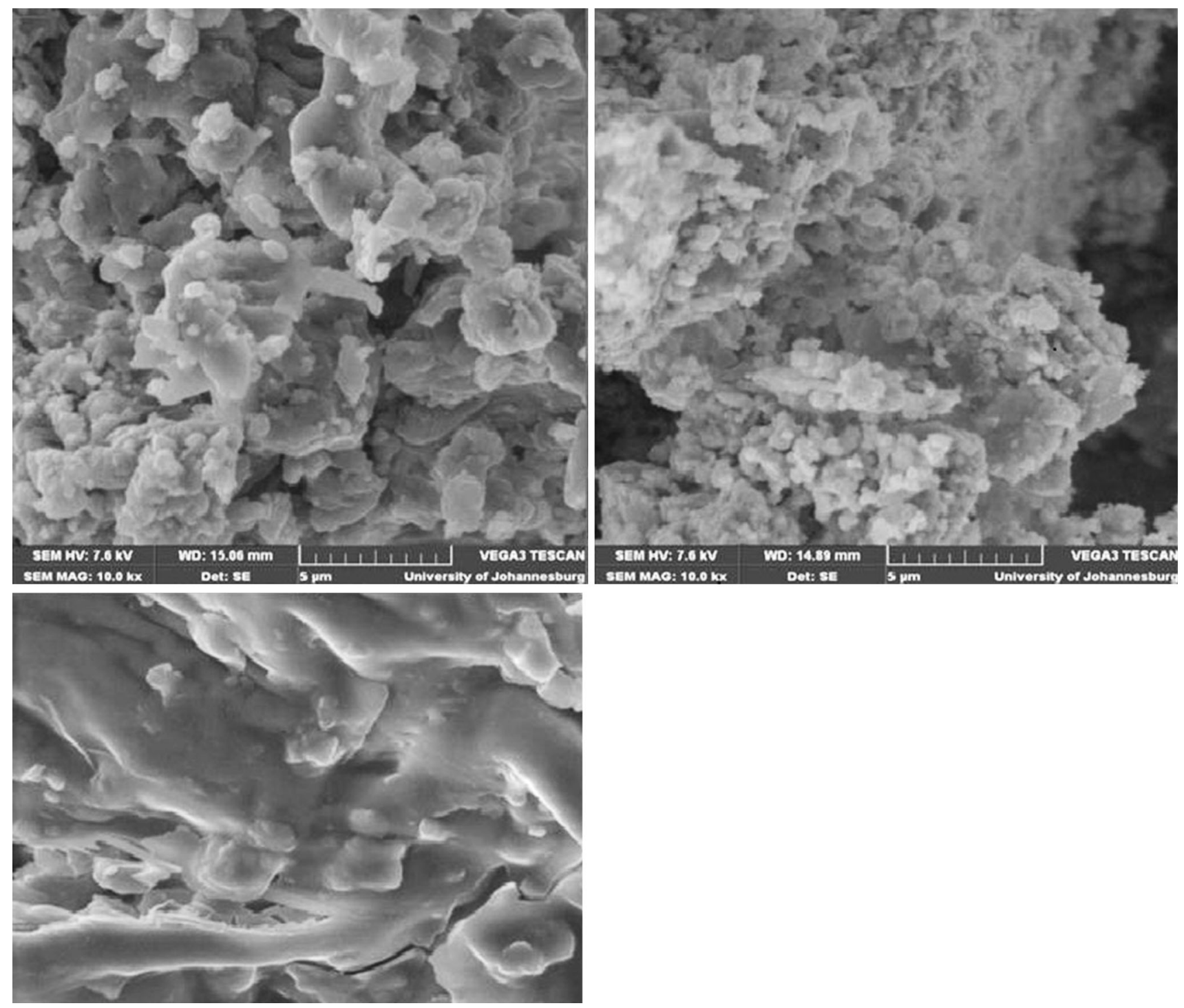

Fig. 1 Scanning electron migrographs showing the surface texture and morphology of ESM, ES and OP

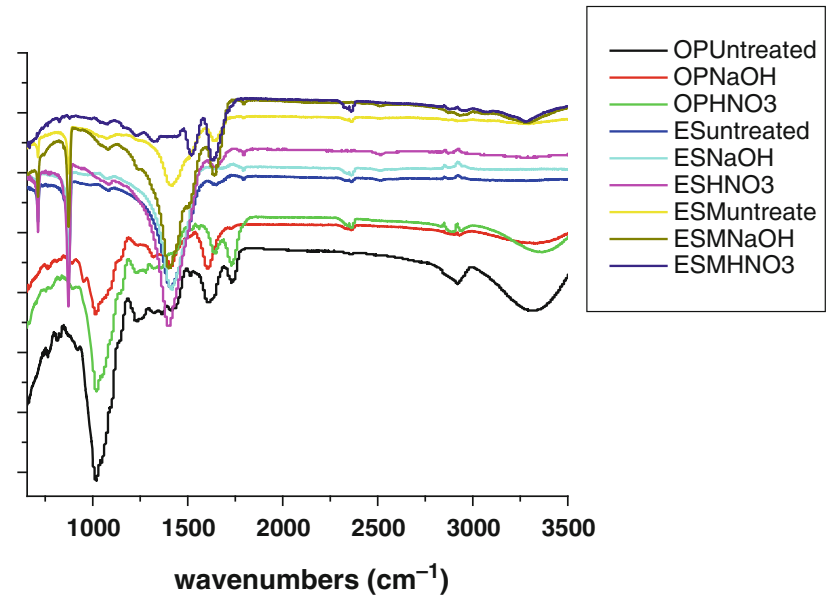

Fig. 2 IR spectra for untreated and treated low-cost adsorbents retained. There was a new peak at $1,024,2,357 \mathrm{~cm}^{-1}$ and a shift in the peak position from 2,919 to $2,887 \mathrm{~cm}^{-1}$ and from 3,309 to $3,346 \mathrm{~cm}^{-1}$ signifying the formation of isocyanates from the parent $\mathrm{C}=\mathrm{O}, \mathrm{CN}$ and $\mathrm{C}=\mathrm{C}$ bonds.

ES did not show much activity in terms of functional group modification on chemical treatment with both $\mathrm{NaOH}$ and $\mathrm{HNO}_{3}$. However, of note is the presence of the peaks at $3,314-3,334 \mathrm{~cm}^{-1}$ and $2,361 \mathrm{~cm}^{-1}$ for ES treated with both $\mathrm{NaOH}$ and $\mathrm{HNO}_{3}$ signifying the presence of $-\mathrm{OH}$ and isocyanates or alkynes, respectively. Treatment with $\mathrm{HNO}_{3}$ introduces a peak at $3,315 \mathrm{~cm}^{-1}$ because of the $\mathrm{C}-\mathrm{H}$ stretching vibrations of alkanes. Looking at the ESM before and after chemical treatment reveals that treatment with $\mathrm{NaOH}$ introduces the isocyanates, nitriles, $\mathrm{O}-\mathrm{C}$ of acids and the $\mathrm{C}=\mathrm{O}$ amide bands as evidenced by the peaks at $2,360,1,235$, and $1,080 \mathrm{~cm}^{-1}$, respectively. However, 
Fig. 3 Adsorption profile of As and $\mathrm{Se}$
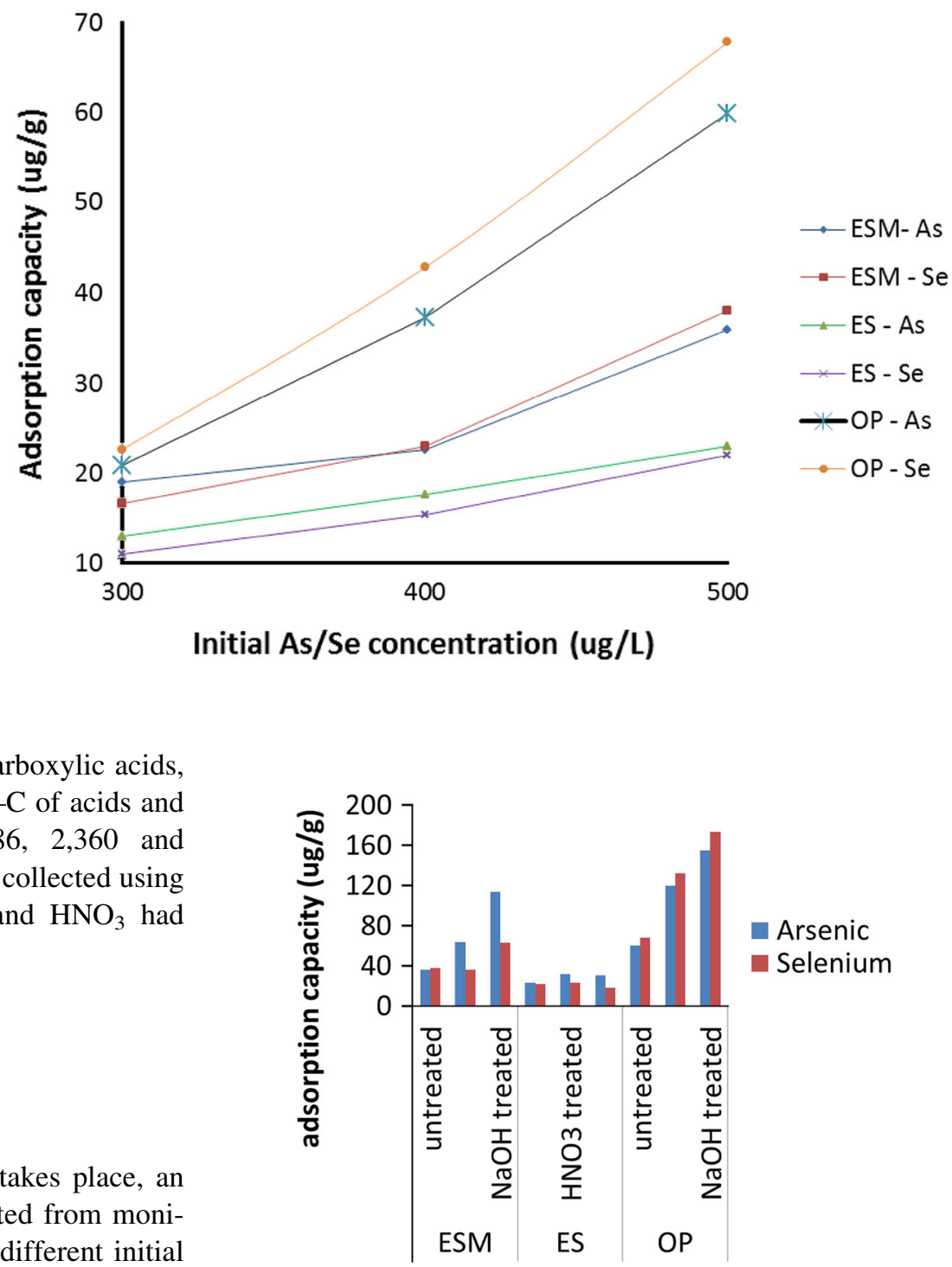

Fig. 4 Effect of chemical modification on the adsorption capacities

\section{Effect of adsorbent chemical treatment on the adsorption}

After successful modification of the adsorbents, as confirmed by FT-IR spectroscopy, these adsorbents were then tested for any improvement or decline in terms of the adsorption and the results are depicted in Fig. 4. Untreated ESM and ES showed no difference in the adsorption of As and Se, even though ESM adsorbed As and Se more than ES. This could be a result of the presence of amines, amides and carboxylic acids in ESM, which are not present in ES. After chemical treatment with $\mathrm{HNO}_{3}$, an increase in As adsorption was evident possibly because of the introduction of positive $\mathrm{O}-\mathrm{C}$ of acids, $\mathrm{O}-\mathrm{H}$ bending and $\mathrm{C}-\mathrm{O}-$ $\mathrm{H}$ bending vibrations, which could promote the adsorption of As. With $\mathrm{NaOH}$ modification, a further increase is observed probably because of the addition of nitriles and 
Fig. 5 Effect of contact time on the adsorption

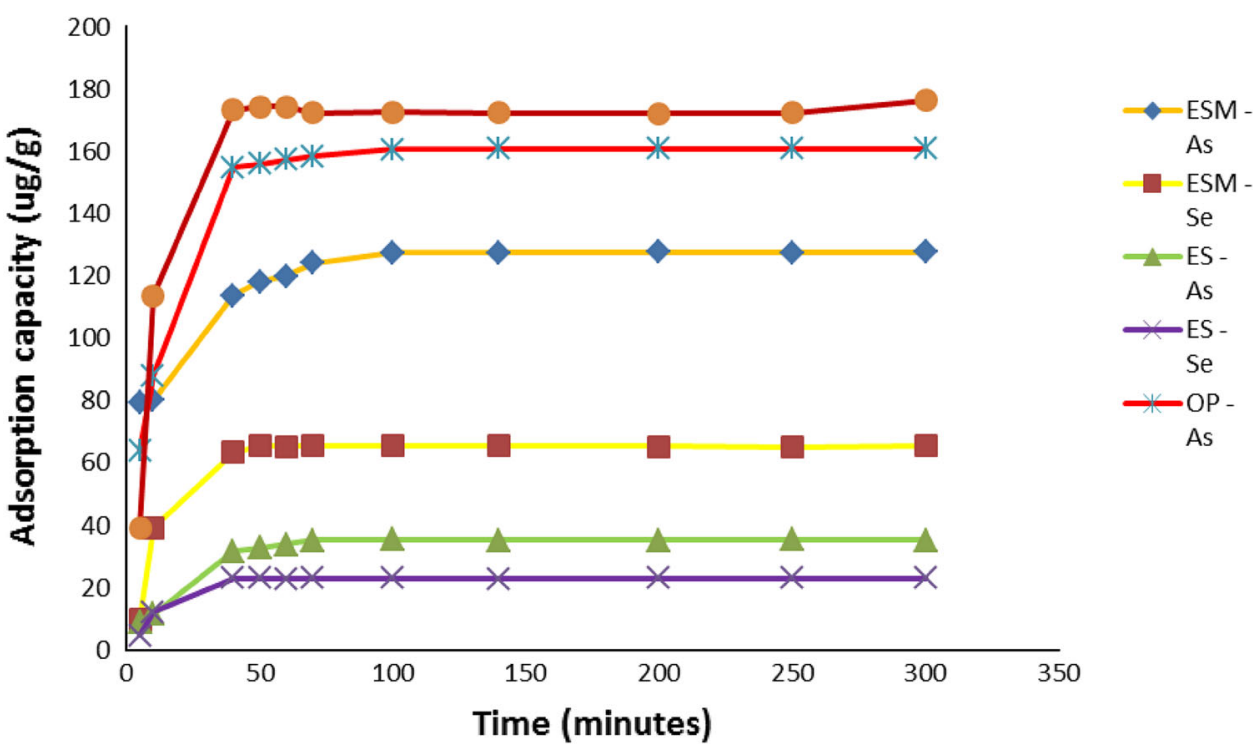

$\mathrm{C}=\mathrm{O}$ bending vibrations to the functional groups already present in $\mathrm{HNO}_{3}$-treated ESM.

Untreated OP showed a slight difference in the adsorption of As and Se with As adsorbed more, suggesting that the functional groups present in OP are better suited to As than Se adsorption. In addition, the surface morphology could play a part here because the overall adsorption of As and Se by OP is better than that of ESM and ES. The adsorption increases uniformly with $\mathrm{HNO}_{3}$ treatment and reaches a peak with $\mathrm{NaOH}$ treatment from which a conclusion may be drawn that the presence of $\mathrm{C}=\mathrm{O}$ stalls the adsorption of both $\mathrm{As}$ and $\mathrm{Se}$, yet the $\mathrm{C}=\mathrm{C}$ is better oriented to adsorb the adsorbates. Amines, amides, isocyanates and arenes improve the adsorption of both As and Se because of their unsaturation and hence they can form fairly strong interactions with the adsorbates, consequently promoting adsorption.

\section{Effect of contact time on the adsorption}

"Effect of adsorbent chemical treatment on the adsorption" of this communication showed that ESM and OP treated with $\mathrm{NaOH}$ and $\mathrm{ES}$ treated with $\mathrm{HNO}_{3}$ performed better in terms of adsorption. In order to investigate the effect of contact time, only these three were studied and the results are presented in Fig. 5. Generally, the adsorption seemed to be adsorbate-dependent rather than adsorbent-dependent, with Se adsorption reaching a maximum at around $50 \mathrm{~min}$ whilst As adsorption reached a maximum just after $100 \mathrm{~min}$. This could be attributed to the size of these toxins and further the stability of the interactions formed between adsorbent and adsorbate, without disregarding the dynamics of the compounds under study. Either the As takes some time to form a strong interaction with the adsorbents or the

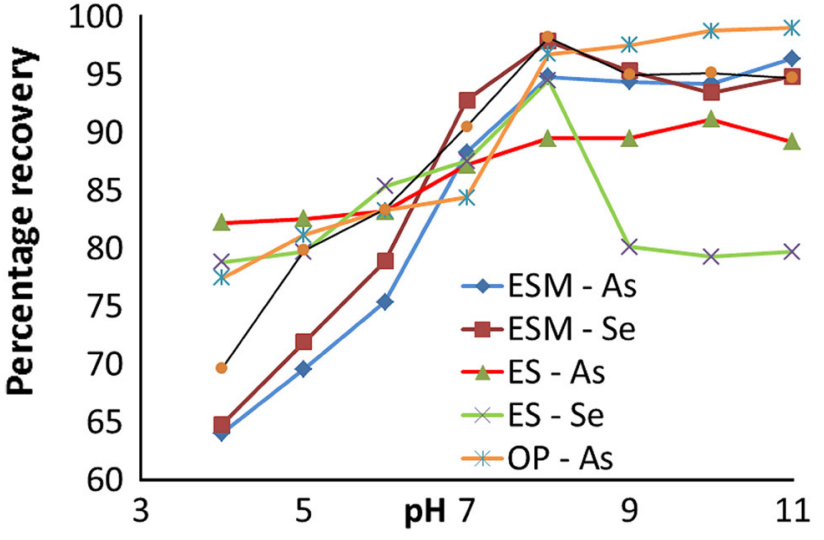

Fig. 6 Effect of the $\mathrm{pH}$ on desorption

Se reaction kinetics are faster, hence they exhaust their adsorption sites faster than As does. As shown in Fig. 5, the results of the adsorption follow the pattern $\mathrm{OP}>\mathrm{ESM}>\mathrm{ES}$ and there is not much difference in the adsorption of As and Se by OP and also by ES, yet there was a difference in the adsorption of As and Se by ESM.

\section{Effect of the $\mathrm{pH}$ on As/Se desorption}

The ability to desorb adsorbates after adsorption is important because it allows the adsorbent to be reused over and over again and again. The desorption is known to be highly dependent on the $\mathrm{pH}$ of the sample solution ( $\mathrm{Li}$ et al. 2012; Feng et al. 2009; Liu et al. 2012). With most adsorptions well documented to successfully take place at $\mathrm{pH} 7$ and above, a desorption $\mathrm{pH}$ of above $\mathrm{pH} 7$ would be desirable because it would not compromise the adsorption capacity. The desorption pattern was investigated from $\mathrm{pH}$ 4-11 with $\mathrm{pH}$ adjustments achieved with concentrated 
Fig. 7 Freundlich adsorption isotherm analysis

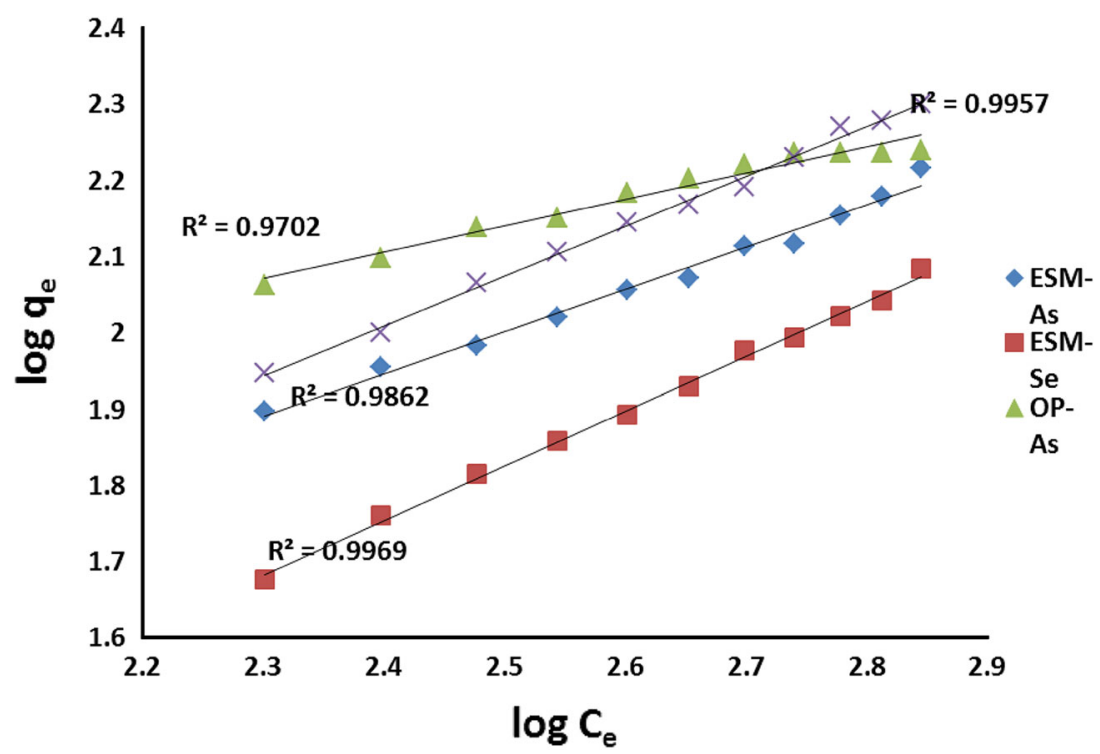

Fig. 8 Langmuir isotherm analysis

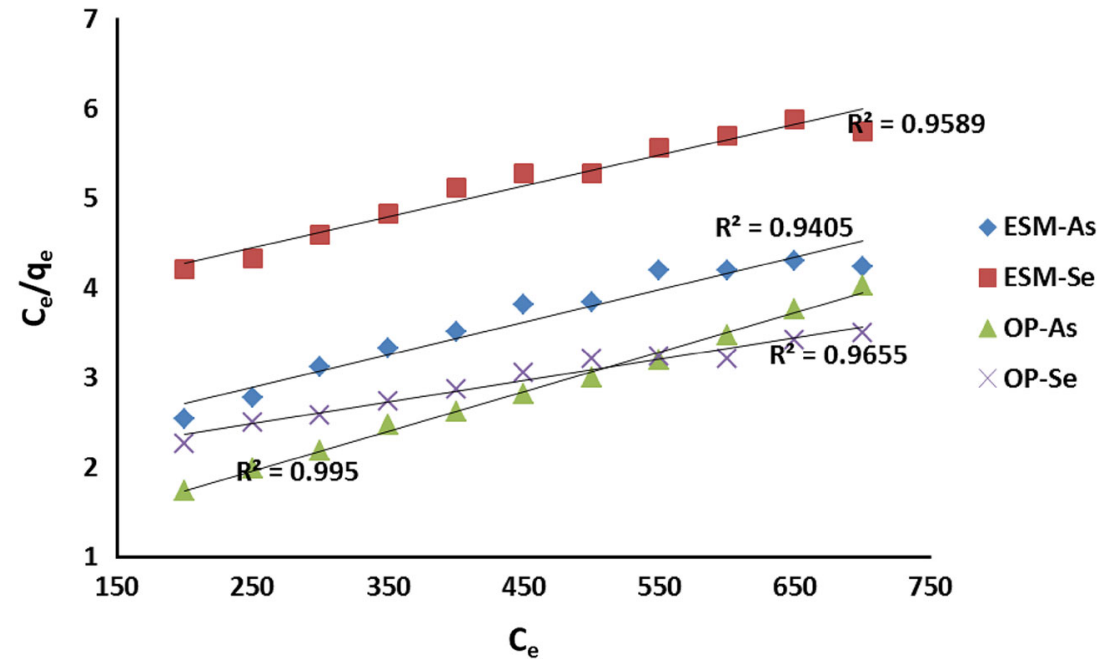

$\mathrm{NaOH}$ and $\mathrm{HNO}_{3}$ to avoid altering the initial concentration of both As and Se. The resulting trends are shown in Fig. 6 and they show that, in general, the desorption is adsorbatedependent as maximal desorption of $\mathrm{Se}$ is observed at $\mathrm{pH} 8$ whilst for As, it is constant at $\mathrm{pH} 10$ for all adsorbents. Throughout the entire $\mathrm{pH}$ range studied, the desorption percentage was above $60 \%$ and improved with an increase in $\mathrm{pH}$ peaking at $\mathrm{pH} 8$ for $\mathrm{Se}$ and at $\mathrm{pH} 10$ for As. Beyond the acidic range, the overall desorption was above $85 \%$ probably because of the semi-rigid interactions formed between adsorbent and adsorbate, which could have been more rigid in the acidic $\mathrm{pH}$ range. Worth noting is the desorption path of Se using ES; beyond $\mathrm{pH} \mathrm{8,} \mathrm{there} \mathrm{was} \mathrm{a}$ gradual decline in the desorption percentage probably because at $\mathrm{pH}$ levels higher than $\mathrm{pH} 8$, the adsorbed $\mathrm{Se}$ forms mostly permanent bonds with the ES restricting the reusability of ES for Se removal to only one successful run.
For subsequent adsorption studies, the sample $\mathrm{pH}$ was kept constant at $\mathrm{pH} 8.5$ to accommodate both the adsorption of As and Se.

Adsorption profile

Figures 7 and 8 show the adsorption isotherms for both As and Se, whereby two adsorption models, namely Langmuir and Freundlich, were used to fully describe the data at equilibrium. Adsorption behaviour was investigated using $0.5 \mathrm{~g}$ of adsorbent in $100 \mathrm{ml}$ of metal solutions in the range 200-700 $\mu \mathrm{g}^{-1}$ at a temperature of $22{ }^{\circ} \mathrm{C}$. Langmuir isotherms are postulated using the modified Langmuir equation:

$\frac{C_{\mathrm{e}}}{q_{\mathrm{e}}}=\frac{1}{Q_{0} b}+\frac{C_{\mathrm{e}}}{Q_{0}}$ 
Table 1 Analysis of real wastewater effluent samples

\begin{tabular}{|c|c|c|c|c|c|c|c|}
\hline \multirow[t]{2}{*}{ Element } & \multirow[t]{2}{*}{$\mathrm{C}_{\mathrm{i}}\left(\mu \mathrm{g} \mathrm{1^{-1 } )}\right.$} & \multicolumn{3}{|l|}{ Orange peels } & \multicolumn{3}{|c|}{ Eggshell membranes } \\
\hline & & $\mathrm{AC}\left(\mu \mathrm{g} \mathrm{g}^{-1}\right)$ & $\% R$ & $\% \mathrm{RC}$ & $\mathrm{AC}\left(\mu \mathrm{g} \mathrm{g}^{-1}\right)$ & $\% R$ & $\% \mathrm{RC}$ \\
\hline As & 245.1 & 84.4 & 68.9 & 96.7 & 66.3 & 54.1 & 97.8 \\
\hline $\mathrm{Se}$ & 197.3 & 73.7 & 74.8 & 93.9 & 46.75 & 47.3 & 95.1 \\
\hline $\mathrm{Pb}$ & 301.8 & 35.4 & 23.4 & 90.7 & 35.05 & 23.22 & 93.3 \\
\hline $\mathrm{Cd}$ & 84.2 & 11.5 & 27.3 & 94.1 & 14.7 & 34.9 & 94.6 \\
\hline $\mathrm{Hg}$ & 72.1 & 8.7 & 24.1 & 93.3 & 6.25 & 17.3 & 97.5 \\
\hline
\end{tabular}

Table 2 Results for Langmuir and Freundlich models

\begin{tabular}{ccccccc}
\hline & \multicolumn{2}{l}{ Langmuir } & & \multicolumn{2}{l}{ Freundlich } & $\begin{array}{l}\text { Best } \\
\text { model }\end{array}$ \\
\cline { 2 - 3 } & $R^{2}$ & $\begin{array}{l}\text { Adsorption } \\
\text { capacity }\end{array}$ & & $\begin{array}{l}\text { Adsorption } \\
\text { capacity }\end{array}$ & \\
\hline $\begin{array}{c}\text { ESM- } \\
\text { As }\end{array}$ & 0.9405 & 0.036 & 0.9862 & 0.5562 & Freundlich \\
$\begin{array}{c}\text { ESM- } \\
\text { Se }\end{array}$ & 0.9589 & 0.034 & 0.9969 & 0.7071 & Freundlich \\
$\begin{array}{c}\text { OP- } \\
\text { As }\end{array}$ & 0.9950 & 0.044 & 0.9702 & 0.3450 & Langmuir \\
$\begin{array}{c}\text { OP- } \\
\text { Se }\end{array}$ & 0.9655 & 0.024 & 0.9957 & 0.655 & Langmuir \\
\hline
\end{tabular}

where $q_{\mathrm{e}}$ is the amount of metals adsorbed in $\mu \mathrm{g} \mathrm{g}{ }^{-1} ; C_{\mathrm{e}}$ is the metal concentration at equilibrium in $\mu \mathrm{g} \mathrm{1^{-1 }} ; Q_{0}$ is the monolayer maximum adsorption capacity of adsorbent $\left(\mu \mathrm{g} \mathrm{g}^{-1}\right) ; b$ is the adsorption constant $\left(1 \mu \mathrm{g}^{-1}\right)$.

A plot of $C_{\mathrm{e}} / q_{\mathrm{e}}$ against $C_{\mathrm{e}}$ should give a straight line with $1 / Q_{0}$ the slope and the intercept given by $1 / Q_{0} b$.

Apart from Langmuir plots which only account for monolayer coverage of the adsorbent surface, the Freundlich isotherm has been used to incorporate the role of substrate-substrate interaction on the surface of the adsorbent. The linear form of the Freundlich equation is given by

$\log q_{\mathrm{e}}=\log k_{\mathrm{f}}+\frac{1}{n} \log C_{\mathrm{e}}$

where $k_{\mathrm{f}}$ and $n$ are related to the adsorption capacity and extent of adsorption, respectively.

A plot of $\log q_{\mathrm{e}}$ against $\log C_{\mathrm{e}}$ gives a straight line with $\log k_{\mathrm{f}}$ the intercept and the slope given by $1 / n$.

From the analysis of both the Langmuir and Freundlich plots, it can be concluded that the adsorption of As and Se by ESM treated with $\mathrm{NaOH}$ follows the Freundlich adsorption model whilst for the $\mathrm{NaOH}$-treated OP, adsorption of As follows the Langmuir adsorption model, yet adsorption of Se follows the Freundlich adsorption isotherm. This suggests that even though adsorption patterns are known to be adsorbate-dependent, they are partly adsorbent-dependent.
Moreover, for the adsorption of the two metals with ESM and OP, the experimental data obtained were analysed with Langmuir and Freundlich isotherms and the results are recorded as shown in Table 2.

The results reveal that the adsorption of both arsenic and selenium on the ESM prescribed to the Freundlich model. This implies that the interaction was a multi-site adsorption for heterogeneous surfaces especially for organic compounds and highly interactive species (Freundlich 1906). Physical adsorption due to van der Waals forces of attraction could also have contributed to the interaction phenomenon (Bayrak 2003). The ESM is a membrane to selectively permeate a flow of fluids by osmosis, which is basically a physical process. The adsorption of both arsenic and selenium on OP was by monolayer adsorption. Langmuir (1918) model describes a monolayer adsorption and it indicates a chemisorption mechanism (Deng et al. 2003). The existence of functional groups on OP created sites for metal attachment.

\section{Analysis of actual water samples}

After successful optimisation of the contact time, sample $\mathrm{pH}$ and the effects of chemical treatment on the adsorption, $\mathrm{NaOH}$-treated OP and ESM were then selected for the adsorption from actual domestic wastewater effluent samples. The results are shown in Table 1 where AC is the adsorption capacity, $\% R$ is the percentage of pollutants removed and $\% \mathrm{RC}$ is the percentage amount of pollutants recovered. These samples were found to contain As, Se, $\mathrm{Pb}, \mathrm{Cd}$ and $\mathrm{Hg}$, with $\mathrm{As}$ and $\mathrm{Se}$ levels above the maximum permissible limit for wastewater effluents, at concentrations of 245.1 and $197.4 \mu \mathrm{g} \mathrm{l}^{-1}$, respectively. On adsorption with $\mathrm{N}$-treated OP, adsorption capacities of 84.4, 73.7, 35.4, 11.5 and $72.1{\mu \mathrm{g} \mathrm{g}^{-1}}$ were achieved for $\mathrm{As}, \mathrm{Se}, \mathrm{Pb}$, $\mathrm{Cd}$, and $\mathrm{Hg}$, respectively, with per cent recoveries of more than $90 \%$ for all the compounds. With $\mathrm{NaOH}$-treated ESM, removal efficiencies of only 66.3, 46.75, 35.05, 14.7 and $6.25 \mathrm{\mu g} \mathrm{g}^{-1}$ were achieved for $\mathrm{As}, \mathrm{Se}, \mathrm{Pb}, \mathrm{Cd}$ and $\mathrm{Hg}$, respectively, with recoveries greater than $90 \%$. Although the ESM also performed well, the adsorption by OP 
Table 3 Analysis of CRM-CA615

\begin{tabular}{llll}
\hline Element & $\begin{array}{l}\text { Certified value } \\
\left(\mu \mathrm{g}^{-1}\right)\end{array}$ & $\begin{array}{l}\text { Our value } \\
\left(\mu \mathrm{g}^{-1}\right)\end{array}$ & $\begin{array}{l}\text { Relative error } \\
(\%)\end{array}$ \\
\hline $\mathrm{As}$ & 9.9 & $9.76 \pm 0.362$ & 1.4 \\
$\mathrm{Fe}$ & 5.11 & $4.98 \pm 0.513$ & 2.5 \\
$\mathrm{~Pb}$ & 7.1 & $7.078 \pm 0.196$ & 0.3 \\
\hline
\end{tabular}

reduced the amount of $\mathrm{As}$ and $\mathrm{Se}$ in solution to the admissible levels of 100 and $150 \mu \mathrm{g} 1^{-1}$, respectively.

Data validation

Apart from performing statistical data analysis and achieving per cent relative standard deviation (\%RSD) of $<5 \%$, and calibration curves with correlation coefficients of 0.9995 and 0.9991 for arsenic and selenium, respectively, it was important to complement these data with the analysis of certified reference materials. Certified reference materials are sold with certificate values; they are used for method validation and to verify the correct use of a method. The certified reference material (ERM-CA615) was analysed and the results are presented in Table 3. The results showed agreement with the certified values of the reference material (ERM-CA 615) with a relative error of $2.5 \%$.

\section{Conclusion}

ESM, ES and OP have been successfully modified using $\mathrm{HNO}_{3}$ and $\mathrm{NaOH}$, and the results of the FT-IR spectra confirmed the modification of the functional groups present. Furthermore, the difference in functional groups of the untreated adsorbents has been confirmed by FT-IR results and scanning electron microscope images showed the differences in surface morphology between the adsorbents. Both the functional groups and the surface orientation were observed to be linked to the performance of the adsorbents in the remediation of both As and Se. TGA studies showed that even though ES were the least adsorbing and dense in terms of the availability of functional groups, they are thermally stable as they only decomposed beyond $700{ }^{\circ} \mathrm{C}$; yet the ESM and OP, which performed better than ES, degraded only after $300{ }^{\circ} \mathrm{C}$, which is still acceptable because the actual temperatures in an adsorption process would not be that high. Better performance of $\mathrm{NaOH}$-treated OP and ESM was experienced at contact times of $100 \mathrm{~min}$ and a sample $\mathrm{pH}$ of 8.5 with OP being able to reduce the amount of both As and Se to acceptable levels with selectivities towards As and Se is greater than 1 .
Acknowledgments This work would not have been successful without the financial backing of the Faculty of Science (University of Johannesburg, South Africa) and the DST/Mintek Nanotechnology Innovation Centre (NIC) (MINTEK, South Africa).

\section{References}

Abdel OE, Reiad NA, Elshafei MM (2011) A study of the removal characteristics of heavy metals from wastewater by low-cost adsorbents. J Adv Res 2(4):297-303. doi:10.1016/j.jare.2011.01. 008

Babel S, Kurniawan TA (2003) Low-cost adsorbents for heavy metals uptake from contaminated water: a review. J Hazard Mater 97:219-243

Banerjee K, Amy GL, Prevost M, Nour S, Jekel M, Gallagher PM, Blumenschein CD (2008) Kinetic and thermodynamic aspects of adsorption of arsenic onto granular ferric hydroxide (GFH). Water Res 42:3371-3378. Available at:http://www.ncbi.nlm.nih. gov/pubmed/18538818. Accessed 20 July 2012

Bayrak Y (2003) Adsorption isotherms in bleaching hazelnut oil. J Am Oil Chem Soc 80(11):1143-1146

Bleiman N, Mishael YG (2010) Selenium removal from drinking water by adsorption to chitosan-clay composites and oxides: batch and columns tests. J Hazard Mater 183(1-3):590-595. doi:10.1016/j.jhazmat.2010.07.065

Cerino-Córdova FJ, Díaz-Flores PE, García-Reyes RB, Soto-Regalado E, Gómez-González R, Garza-González MT, BustamanteAlcántara $\mathrm{E}$ (2013) Biosorption of $\mathrm{Cu}(\mathrm{II})$ and $\mathrm{Pb}$ (II) from aqueous solutions by chemically modified spent coffee grains. Int J Environ Sci Technol 10:611-622

Chen M, An M (2012) Selenium adsorption and speciation with $\mathrm{Mg}$ $\mathrm{FeCO}_{3}$ layered double hydroxides loaded cellulose fibre. Talanta 95:31-35. doi:10.1016/j.talanta.2012.03.038

Cheng X, Liu J, Zou S (2011) Monitoring of heavy metal cadmium in environmental water sample by eggshell membrane preconcentration coupled with GF-AAS. International Conference on Electric Technology and Civil Engineering (ICETCE), 22-24 April 2011. Lushan, China, pp 1356-1359. doi: 10.1109/ ICETCE.2011.5776532

Deng S, Bai R, Cheng PJ (2003) Aminated polyacrylonitrile fibers for lead and copper removal. Langmuir 19:5058-5064

Deng PY, Liu W, Zeng BQ, Qiu YK, Li LS (2013) Sorption of heavy metals from aqueous solution by dehydrated powders of aquatic plants. Int J Environ Sci Technol 10:559-566

Dhakal RP, Ghimire KN, Inoue K (2005) Adsorptive separation of heavy metals from an aquatic environment using orange waste. J Int Adsorpt Soc 79:182-190

Feng NC, Guo XY (2012) Characterization of adsorptive capacity and mechanisms on adsorption of copper, lead and zinc by modified orange peel. Trans Nonferr Met Soc Chin 22(5):1224-1231. doi:10.1016/S1003-6326(11)61309-5

Feng NC, Guo XY, Liang S (2009) Enhanced Cu (ن்) adsorption by orange peel modified with sodium hydroxide. Trans Nonferr Met Soc Chin 20(December):s146-s152. doi:10.1016/S10036326(10)60030-1

Feng NC et al (2011) Biosorption of heavy metals from aqueous solutions by chemically modified orange peel. J Hazard Mater 185(1):49-54. doi:10.1016/j.jhazmat.2010.08.114

Freundlich HMF (1906) Over the adsorption in solution. Z Phys Chem 57A:385-470

González EA et al (2011) Density functional theory study of selenium adsorption on Fe(110). Appl Surf Sci 257:6878-6883. Available at: http://linkinghub.elsevier.com/retrieve/pii/S016943321100 3758. Accessed 01 Aug 2012 
Hamilton SJ (2004) Review of selenium toxicity in the aquatic food chain. Sci Total Environ 326:1-31

Haque S, Johannesson KH (2006) Arsenic concentrations and speciation along a groundwater flow path: the Carrizo Sand aquifer, Texas, USA. Chem Geol 228:57-71

Hung DQ, Nekrassova O, Compton RG (2004) Analytical methods for inorganic arsenic in water: a review. Talanta 64:269-277

Igwe JC, Abia AA, Ibeh CA (2008) Adsorption kinetics and intraparticulate diffusivities of $\mathrm{Hg}$, As and $\mathrm{Pb}$ ions on unmodified and thiolated coconut fiber. Int $\mathbf{J}$ Environ Sci Technol 5(1):83-92

Jain CK, Ali I (2000) Arsenic: occurrence, toxicity and speciation techniques. Water Res 34(17):4304-4312

Kamsonlian S et al (2012) Biosorptive behaviour of mango leaf powder and rice husk for arsenic (III) from aqueous solutions. Int J Environ Sci Technol 9:565-578

Ladeira ACQ, Ciminelli VSTVST (2004) Adsorption and desorption of arsenic on an oxisol and its constituents. Water Res 38(8):2087-2094. Available at: http://www.ncbi.nlm.nih.gov/ pubmed/15087189. Accessed 01 Aug 2012

Langmuir I (1918) The adsorption of gases on plane surfaces of glass, mica and platinum. J Am Chem Soc 40:1362-1403

Lasheen MR, Ammar NS, Ibrahim HS (2012) Adsorption/desorption of $\mathrm{Cd}$ (II), $\mathrm{Cu}$ (II) and $\mathrm{Pb}$ (II) using chemically modified orange peel: Equilibrium and kinetic studies. Solid State Sci 14(2):202-210. doi:10.1016/j.solidstatesciences.2011.11.029

Li R et al (2012) Exceptional arsenic adsorption performance of hydrous cerium oxide nanoparticles: Part A. Adsorption capacity and mechanism. Chem Eng J 185-186:127-135. Available at: http://linkinghub.elsevier.com/retrieve/pii/S1385894712000642. Accessed 01 Aug 2012

Liu B, Lv X, Wang D, Xu Y, Zhang L, Li Y (2012) Adsorption behavior of As(III) onto chitosan resin with As(III) as template ions. J Appl Polym Chem 125(1):246-253

Litter MI, Morgada ME, Bundschuh J (2010) Possible treatments for arsenic removal in Latin American waters for human consumption. Environ Pollut 158(5):1105-1118. doi:10.1016/j. envpol.2010.01.028

Love K, Thatcher LL (1953) Water. Anal Chem 25(1):65-74

Manna B, Ghosh UC (2007) Adsorption of arsenic from aqueous solution on synthetic hydrous stannic oxide. J Hazard Mater 144:522-531. Available at: http://www.ncbi.nlm.nih.gov/ pubmed/17118543. Accessed 01 Aug 2012

Mistry HD, Pipkin FB, Redman CWG (2012) Selenium in reproductive health. Obstetrics 206(1):21-30. doi:10.1016/j.ajog.2011.07.034

Ngah WSW, Hanafiah MAKM (2008) Removal of heavy metal ions from wastewater by chemically modified plant wastes as adsorbents: a review. J Bioresour Technol 99:3935-3948

Peak D (2006) Adsorption mechanisms of selenium oxyanions at the aluminum oxide/water interface. $\mathbf{J}$ Colloid Interface Sci 303(2):337-345. Available at: http://www.ncbi.nlm.nih.gov/ pubmed/16949599. Accessed 01 Aug 2012

Richardson SD (2001) Water analysis. Anal Chem 73(12):2719-2734

Richardson SD, Ternes TA (2011) Water analysis: emerging contaminants and current issues. Anal Chem 83(12):4614-4648

Tian Y, Wu M, Lin X, Huang P, Huang Y (2011) Synthesis of magnetic wheat straw for arsenic adsorption. J Hazard Mater 193:10-16. Available at: http://www.ncbi.nlm.nih.gov/pubmed/ 21862216. Accessed 01 Aug 2012

Tsai WT, Yang JM, Lai CW, Cheng YH, Lin CC, Yeh CW (2006) Characterization and adsorption properties of eggshells and eggshell membrane. J Bioresour Technol 97:488-493

World Health Organization (WHO) (2008) Guidelines for drinking water quality. WHO, Geneva

Yigit NO, Tozum S, Demirel S (2012) Removal of selenium species from waters using various surface-modified natural particles and waste materials. CLEAN Soil Air Water 40(7):735-745

Zhang Y, Wang W, Lu L, Huang Y, Cao J (2010) Eggshell membrane-based solid-phase extraction combined with hydride generation atomic fluorescence spectrometry for trace arsenic (V) in environmental water samples. Talanta 80(5):1907-1912. doi:10.1016/j.talanta.2009.10.042 